\title{
CONCEPÇÕES E RELATOS DE ADOLESCENTES COM ALTAS HABILIDADES OU SUPERDOTAÇÃO SOBRE ASPECTOS PSICOSSOCIAIS DA SEXUALIDADE
}

\author{
Ana Cláudia Bortolozzi Maia'
}

REIS, V. L. dos. Concepções e relatos de adolescentes com Altas Habilidades ou Superdotação sobre aspectos psicossociais da sexualidade. 20I8. 240 f. Tese (Doutorado) - Faculdade de Ciências e Letras, Universidade Estadual Paulista Júlio de Mesquita Filho, Araraquara, 2018.

A temática da superdotação é bem recente na educação inclusiva e mais ainda na relação dela com o desenvolvimento da sexualidade. Por isso, parece-nos importante apresentar a tese de doutorado intitulada Concepções e relatos de adolescentes com altas habilidades ou superdotação sobre aspectos psicossociais da sexualidade, ${ }^{2}$ defendida por Verônica Lima dos Reis junto ao Programa de Pós-Graduação em Educação Escolar da Universidade Estadual Paulista Júlio de Mesquita Filho (FCLar/UNESP), na linha de pesquisa: sexualidade, cultura e educação sexual, sob a minha orientação. Embora em senso comum se atribua à Superdotação (SD) a ideia de que as pessoas tenham "superpoderes", as características de Altas Habilidades (AH) dos indivíduos diagnosticados com $\mathrm{AH} / \mathrm{SD}$ são muito variadas e podem aparecer isoladamente ou não, em uma ou em várias áreas, tais como: intelectual, acadêmica, psicomotora, artística, etc. Há autores que classificam a superdotação em três tipos: o acadêmico, o produtivo-criativo e o misto (os dois juntos). Além disso, as pessoas com $\mathrm{AH} / \mathrm{SD}$ podem apresentar dissincronismo no processo de desenvolvimento afetivo e esse descompasso pode dificultar os relacionamentos emocionais e sociais.

A tese da autora é a de que adolescentes com $\mathrm{AH} /$ SD têm características que devem ser consideradas no desenvolvimento da sexualidade e no processo de educação sexual. Como parte do público-alvo da educação especial, deve ser considerado em suas especificidades também na área da educação sexual e conhecer suas concepções e informações irá auxiliar na elaboração de propostas de educação sexual que respeitem e valorizem as diversidades.

A pesquisa realizada foi de natureza qualitativa e a autora verificou os aspectos psicossociais da sexualidade de adolescentes com $A H / S D$, procurando revisar sistematicamente a literatura nesta área, investigar o acesso à informações sobre sexualidade, bem como questões da educação sexual desses adolescentes; analisar suas possíveis crenças e valores sexuais; levantar seus relatos sobre conhecimentos, ações e atitudes diante da sexualidade e, elaborar uma proposta de Educação Sexual para o público de adolescentes com AH/SD.

A tese é apresentada na seguinte sequência. Primeiramente uma introdução, seguida de uma justificativa e dos objetivos. Depois uma fundamentação teórica discorrendo sobre os conceitos de adolescência, altas habilidades ou superdotação e a sexualidade, para apresentar o método de pesquisa. A análise e discussões dos resultados foram apresentadas em três etapas:

\section{$\left.I^{a}\right)$ Estudo Teórico}

A autora fez uma revisão sistemática da literatura após levantamento nas bases de dados Biblioteca Virtual de Educação; Biblioteca Virtual de Saúde; Biblioteca Nacional; Education Resources Information Center (ERIC); Catálogo de Teses e Dissertações da Coordenação de Aperfeiçoamento de Pessoal de Nível Superior (CAPES); Scopus; e, Web of Sciense, com os seguintes descritores: "sexualidade", "educação sexual", "orientação sexual", "sexualidade e altas habilidades", "sexualidade e superdotação", "sexualidade e infância", "sexuality", "sexuality and gifteness" e "sexuality and gifted". Foram encontrados apenas sete artigos internacionais.

\section{$2^{\circ}$ ) Estudo Empírico}

Participaram 12 adolescentes (seis meninos e seis meninas), entre 12 e 17 anos diagnosticados com $\mathrm{AH} /$ $\mathrm{SD}$, sendo oito do tipo acadêmico e quatro do tipo produtivo-criativo (artes, desenho, dança e música) que responderam a um questionário on-line elaborado pela

\footnotetext{
' Psicóloga. Professora Assistente Doutora. Coordenadora do Laboratório de Ensino e Pesquisa em Sexualidade Humana (LASEX). Departamento de Psicologia da Universidade Estadual Paulista “Júlio de Mesquita Filho”, Faculdade de Ciências, UNESP, Bauru, SP. E-mail: claudia.bortolozzi@unesp.br 2 Esta pesquisa foi realizada com apoio da CAPES.
} 
pesquisadora a partir de quatro eixos temáticos: caracterização, informações e concepções, crenças, saúde sexual e reprodutiva. O questionário é muito interessante e pode ser utilizado por outros pesquisadores junto ao público adolescente com $\mathrm{AH} / \mathrm{SD}$ ou não.

Os resultados apontam que a família e a escola foram as maiores fontes de informações sobre sexualidade para os/as jovens; os conceitos e crenças sobre sexualidade retrataram conhecimentos científicos. Os meninos, mais que as meninas, apresentam estereótipos de beleza em relação a um corpo considerado bonito. Os preservativos (masculino e feminino) foram reconhecidos como meios para a prevenção da gravidez $(79,2 \%)$ e da prevenção das infecções sexualmente transmissíveis $(83,3 \%)$, enquanto que outros métodos não foram considerados $(49,4 \%)$.

$\left.3^{\circ}\right)$ Elaboração de uma proposta de Educação Sexual para esse público

A proposta apresentada pela autora é muito interessante e tem por base a literatura consultada e os resultados analisados. Ela defende a parceria da escola com a família e a necessidade de uma educação inclusiva que considere o enriquecimento extracurricular para atender diferentes áreas de $\mathrm{AH} / \mathrm{SD}$, também no conteúdo de sexualidade.

Finalmente a autora reconhece os limites do estudo, responde seus objetivos e problematiza sua tese, concluindo que todos os adolescentes, com AH/SD ou não, devem receber educação sexual e, no caso desse público em específico, este processo pode também favorecer o desenvolvimento socioemocional. A temática é instigante e ainda há muitos desafios e problemas de pesquisa a serem desenvolvidos e compartilhados na área da sexualidade.

\section{Contatos com a autora da tese:}

Verônica Lima dos Reis

Psicóloga, doutora em Educação Escolar pelo Programa de Pós-Graduação em Educação Escolar da Universidade Estadual Paulista Júlio de Mesquita Filho (FCLar/UNESP), Araraquara, SP. Atualmente é pós-doutoranda junto a Pós-Graduação em Psicologia do Desenvolvimento e Aprendizagem da Faculdade de Ciências, da UNESP, Bauru, SP. E-mail: verônica.lima.reis@gmail.com 